\title{
O "Burro de Carga" na Admınistração Pública do Brasil (*)
}

\author{
John Rood e Frank Sherwood \\ Tradução de Astério Dardeau VIEIRA
}

OMo é que realmente se processa o trabalho na Administracão Pública Brasileira?

Para grande parte dos países mais desenvolvidos, a questão pode parecer supérflua. Porém, num país em desenvolvimento como o Brasil, onde o emprêgo público tem sido encarado como uma sinecura, mal paga mas sem obrigações especificas, às vêzes causa espanto que se consiga realizar qualquer trabalho.

Uma experiência em dois cursos pelo método do caso, combinada com a análise dos próprios casos apresentados nesses mesmos cursos, dá uma certa idéia de como funciona a burocracia do Govêrno Federal.

O Brasil tem um sistema de administração baseado no "burro de carga", isto é, pequenos grupos de indivíduos em cada um dos ministérios e repartições, que, por uma variedade de motivos, assumem a responsabilidade por todo o trabalho. A presença dêsses "burros de carga" parece ser, de modo geral, uma questão de acidente: podem consistir, por exemplo, num grupo reduzido de servidores saudosos dos "bons tempos" do Govêrno de Getúlio

( ${ }^{*}$ ) Este trabalho é uma amostra da situação existente na Administração Brasileira. Os dados foram obtidos em discussões e trabalhos escolares durante dois cursos ministrados na Escola do Serviço Público do DASP, em 1962, por John Rood, com a assistência de E.J. Jones Jr.

N. do T. - A tradução é feita com autorização do Sr. Robert T. Doland, editor do livro «Perspectives of Brazilian Public Administration», volume I, de que o trabalho faz parte. O livro foi publicado em 1963, sob os auspícios da Escola Brasileira de Administração Pública, da Fundação Getúlio Vargas, e da Escola de Administração Pública da Universidade da Califôrnia do Sul. 
Vargas $\left({ }^{*}\right)$, agora velhos funcionários, acompanhados de uns poucos que entraram mais recentemente, por concurso. Como "burros de carga", não há quem lhes ultrapasse o senso de responsabilidade: uma vez que ninguém mais se dispõe a fazer o trabalho, êles simplesmente preenchem o vácuo.

Esse pequeno grupo tropeça numa série de dificuldades e frustrações, inclusive, em plano de destaque, os problemas criados pelos colegas de repartição e a falta de supervisão adequada. Os outros funcionários geralmente foram nomeados por nepotismo e carecem de habilitação para o cargo; e alguns, os mais protegidos, às vêzes nem comparecem ao trabalho.

\section{CAMPO DE ANÁLISE}

Antes de prosseguir, porém, cumpre apontar as limitações desta análise. Bàsicamente, as informações e idéias aqui apresentadas provêm de duas fontes: a) dois cursos sôbre problemas de supervisão, em que se adotou o método de discussão de casos; e b) aproximadamente, 50 pequenos casos escritos por estudantes brasileiros, sobre vários aspectos da supervisão. Os cursos foram ministrados em 1962, na Escola do Serviço Público do DASP, pelo Professor John Rood, com a colaboração do Professor Edward Jones Jr., e a matrícula em cada um dêles foi limitada a 25 alunos, escolhidos dentre um número bem maior de candidatos. $\mathrm{O}$ método do caso era, para todos êles, uma experiência nova.

Com poucas exceções, o grupo se compunha de funcionários de nivel profissional relativamente baixo. A maioria não tinha funções de supervisão e apenas um havia atingido a posição de Chefe. Assim, a análise tende a ser influenciada pela percepção de quem se encontrava, essencialmente, na posição de receber ordens e diretrizes, o que afeta o conceito de liderança e oferece a aparência de uma significação maior do que realmente tem, como se fôsse o caso de uma amostragem colhida entre niveis funcionais
mais elevados.

\section{O MODÊLO DE REJEIÇÃO DO TRABALHO}

Por que será que todo o serviço da repartição recai nos ombros de uns poucos burros de carga?

A resposta, em essência, reside no sistema político e social, que não recompensa o trabalho.

Como indicamos linhas atrás, na maioria dos casos as nomeações se fazem pelo critério politico e recaem sôbre pessoal do têrço

${ }^{*}$ ) N. do T. Os autores referem-se, naturalmente, à época em que prevalecia o Sistema do Mérito, introduzido no Brasil pelo Presidente Getúlio
Vargas. 
inferior da classe média, sem instrução nem experiência suficientes, e para quem a Administração Pública não passa de uma sinecura. Ulm dos casos citados, por exemplo, refere-se a uma môça recémnomeada, "que entrou na Seção proclamando que queria apenas um emprêgo, trabalho não". Além disso, quase não existe treinamento de iniciação funcional, de modo que o nôvo funcionário, ainda que chegasse devidamente motivado, encontraria dificuldade em saber que tarefa individual lhe estava reservada e que papel essa tarefa iria desempenhar no quadro mais amplo das finalidades da Organização.

A tragédia maior consiste, talvez, no fato de que a situação não se modifica com o tempo, pois não é pequeno o número de funcionários de carreira que, após longos anos de serviço, ainda não descobriram uma função útil a desempenhar. Nesse meio tempo, constituiram familia e aceitaram outros empregos para prover à própria subsistência. Dentro dêsse quadro geral de luta constante e fragmentação de tarefas, torna-se cada vez mais dificil integrá-los nos grupos de "burros de carga". Sua própria presença transforma-se num elemento de corrupção: - chegam tarde, saem cedo e pouco ou nada fazem no escritório. Sua falta de disciplina e de interêsse no serviço, não só torna o trabalho mais difícil, mas, também, cria problemas com o público. Ocasionalmente, os ex cessos praticados dão lugar a medidas disciplinares vindas de cima, medidas essas que, embora atingindo indistintamente a todos os funcionários, na verdade vão ferir mais fundo os "burros de carga".

\section{A FALTA DE APOIO DA CHEFIA}

O tipo de supervisão que se encontra na maioria das repartições públicas infelizmente agrava o problema, em lugar de atenuálo. Em vez de encontrar apoio no chefe, os "burros de carga" geralmente ai se defrontam com mais um fator negativo.

Em parte, êsses problemas surgem porque a supervisão, em si mesma, não é reconhecida no sistema administrativo como uma função que reclama qualidades especiais. Ocorre, também, grande instabilidade no sistema, porque todos os supervisores, de alto a baixo, exercem funções "de confiança", de modo que a competência técnica é menos importante que as boas relações com o pessoal dos escalões superiores.

Não é de surpreender, portanto, que a função de supervisor também seja encarada em têrmos de vantagem pessoal: - supervisionar consiste em ocupar uma posição pela qual se ganha mais. O funcionário de nível inferior aceita uma posição de chefia sem preocupação maior que ao assumir um carg̣o de mera execução. A autoridade que nomeia é capaz de adotar a mesma atitude, já 
que pode muito bem vir a se encontrar em posição análoga e, portanto, sua tendência é para raciocinar nos mesmos têrmos. $\mathrm{E}$ assim acontece ao longo da escala hierárquica, com a preferência pessoal desempenhando papel de alta relevância na nomeação dos
supervisores.

Que tipo de supervisão resulta dêsse sistema? Se a nomeação não se faz à base de capacidade técnica ou de liderança, não há motivo para que êsses fatôres passem a desempenhar papel de relevância na execução do trabalho. No entanto, existe um certo número de supervisores que trabalham pesado, enquanto outros se esforçam muito pouco. De qua!quer modo, na maioria êles encaram a chefia como colocada à parte da unidade administrativa, a freqüentemente não sabem, nem acham que é de sua obrigação saber, o que realmente se passa no dia-a-dia.

O supervisor, em geral, não tem a concepção de que seu papel consiste em facilitar o trabalho da unidade, pelo exercício das funções normais de supervisão, como planejamento, direção e contrôle. Ao contrário, considera que sua tarefa consiste em resolver os problemas que lhe são trazidos à decisão: espera que as coisas aconteçam e cuida de solucionar os assuntos dificeis que lhe desabam sôbre a cabeça. Em certas ocasiões, essa atitude se agrava por incompetência, pusilanimidade e outras fraquezas de ordem

Quando um supervisor atinge o pôsto em circunstâncias dessa natureza, é provável que tenha plena consciência de sua vulnerabilidade. Como sobrevive, então? Ao que tudo indica, pouco adianta manter sua unidade bem organizada; em outras palavras, a virtude
não compensa.

O recurso muito em voga, como vigoroso instrumento de poder, é a famosa técnica de se fazer indispensável na complicação burocrática que geralmente prevalece nas repartições ministeriais. Para isso o supervisor lança mão de dois artifícios: - chama a si a assinatura de todos os papéis e mantém em segrêdo a rotina do trabalho, que só êle conhece. Assim, quando se ausenta, ninguém sados.

Esta área privativa de conhecimentos administrativos dá-lhe, pois, a certeza de que seu afastamento teria reflexos imediatos na produção da Seção. Apesar disso tudo. entretanto, na maioria dos casos os supervisores se ressentem de falta de segurança: - lutam vivem sob o temor obter o apoio dos respectivos superiores e por pequena que sejonstante de que uma falha de sua unidade, altos. 
Em circunstâncias como essas, são inevitáveis as perturbações, de tempos a tempos. O supervisor, sem contato com sua unidade, com as vistas voltadas para outros assuntos, de repente se vê a braços com uma situação ameaçadora. Mesmo que tenha consciência de que as coisas não andavam muito bem, de modo geral sempre evitou envolver-se nos problemas. Agora, porém, é preciso agir. Que fazer?

De modo geral, sua atuação é ad hoc, e às vêzes devastadora do pouco que restava do moral do grupo. Sua preocupação básica é eliminar o problema com o minimo possivel de agitação, pois qualquer repercussão maior poderia colocar sua posição em xeque, como seria o caso de funcionários descontentes apelarem para amizades politicas, o que certamente criaria uma situação embaraçosa. Assim, ao procurar uma solução, o supervisor não demonstra maior interêsse em resolver o problema em si, ou impedir seu reaparecimento.

Uma vez que considerações dessa ordem não casam com seu interêsse imediato de auto-preservação e não se incluem no seu conceito de responsabilidade pela supervisão, o supervisor geralmente adota medidas destinadas a afastar o problema do caminho. Pouco importa que o culpado seja premiado, o inocente punido, - êrro confirmado, o "burro de carga" desmoralizado e a Seção levada à ruina: - se o problema desaparece, o chefe se dá por satisfeito. É claro que o problema pode reaparecer, ou a decisão pode acarretar conseqüências de natureza grave, mas, afinal de contas, os supervisores conquistaram as respectivas posições por uma questão de sorte, e com um pouquinho mais talvez seja possivel conservá-las.

\section{A TOLERÂNCIA COMO FATOR SIGNIFICATIVO NO AMBIENTE DE TRABALHO}

Embora haja tensões entre supervisores e funcionários no decurso do trabalho, o impacto dessas emoções se neutraliza, em grande parte, pelo alto grau de tolerância que parece incrustado na cultura brasileira. Por uma grande variedade de motivos, alguns talvez relacionados com o clima, o brasileiro tende a aceitar as falhas e imperfeições do sistema social, com muito mais facilidade que o norte-americano, por exemplo. Na verdade, essas imperfeições de há muito são aceitas como um sistema de vida.

Assim, o funcionário brasileiro de categoria inferior, lutando com tôda sorte de dificuldades na sua vida privada e assoberbado com um sem número de problemas no ambiente de trabalho, demonstra vigoroso senso de fraternidade e solidariedade em relação ao colega em condições semelhantes. É uma fraternidade que 
nasce da comunhão de incertezas, problemas e dificuldades, gerando a necessidade de cerrar fileiras, porque amanhã o infortúnio pode recair sôbre êle próprio. Essa tolerância se torna mais evidente quando um colega, por ignorância, falta de treinamento ou simples má sorte, cria um problema ou entra em choque com o
supervisor.

Há, também, a reconhecer, a circunstância de que a maioria dos funcionários não recebeu mais que instrução primária, e muito pouco treinamento, na melhor das hipóteses. Conseqüentemente, o brasileiro não apenas aceita, mas também desculpa a repetição de falhas e irregularidades, e não espera que tal situação venha a se corrigir. O problema da inadequação é tão grande e generalizado, que é preciso coexistir com êle, de bom humor se possivel.

Há uma coisa, entretanto, que o brasileiro exige do colega nessa situação: - boa-fé no trato com os companheiros. O trabalhador brasileiro aceita uma porção de coisas na presunção de que o infrator não tem a intenção de criar problemas. Quando, porém, se evidencia má fé, a explosão pode ser de graves conseqüências. Em outras palavras, o trabalhador brasileiro pode tolerar repetidas perturbações em suas atividades, mas o que êle não tolera E uma atitude deliberada de criar problemas dessa ordem.

Embora êsse humanismo não possa deixar de impressionar, cumpre reconhecer que a tolerância se opõe à criação de um ambiente propicio à reforma, pois o trabalhador brasileiro, tolera, não apenas o que milita em seu próprio prejuizo, mas, igualmente, em prejuizo do Serviço Público em geral.

Assim, a disposição para aceitar irregularidades de caráter pessoal gera muito pouco entusiasmo por parte do Govêrno, no sentido de melhorar o desempenho funcional. Constantemente, nas discussões de classe, maior ênfase se dava ao papel do Govêrno como promotor do bem-estar social, que como empregador orientado no sentido da eficiência. $O$ argumento era que talvez fôsse preferivel manter o nivel de ineficiência dos serviços governamentais, alguns até desnecessários, em benefício dos funcionários que - Govêrno emprega para prover às suas necessidades pessoais, o que é muito mais importante que a eficiência no trabalho. O Go-

O problema, entretanto, não se restringe à aceitação de irregularidades no ambiente de trabalho, pois há indícios de que essa atitude de tolerância conduz à corrupcão. Muito se discutiu sôbre os limites que se impõem à proteção devidà por um colega ao outro, como, por exemplo, no caso de falsificacão do livro ou cartão de ponto. Esse comportamento deveria, realmente, ser considerado um ato de corrupção? O grupo manifestou sérias dúvidas de que 
pequenas infrações como essa, das normas de conduta, devessem ser consideradas falta grave, ou guardassem qualquer relação com possiveis violações de maior vulto, como o peculato e subôrno. Outra questão que se levantou é se a intolerância das falhas humanas influi em sentido positivo ou negativo, no que se refere à corrupção. A resposta do pessoal brasileiro revelou uma atitude curiosa em relação ao contrôle. Em teoria, disse um grande número de alunos, o chefe menos humano deveria estar em condições mais propícias para reprimir a corrupção, mas na prática não era isso o que ocorria. Embora concordassem que a falta de organização e de contrôle dava maior liberdade de ação aos "espertinhos", não acreditavam que um tratamento mais humano significasse necessàriamente a tolerância dos mal intencionados.

\section{CONCLUSÕES}

Esta breve descrição dos "burros de carga" na administração pública do Brasil põe em evidência graves contradições, como, aliás, ocorre em outros aspectos da vida brasileira. Por um lado, temos uma administração bàsicamente desorganizada, em têrmos de utilização dos próprios recursos. Por outro, o sistema de valorização do grupo social é notável por sua integração e apoio reciproco dos respectivos membros. Não resta a menor dúvida de que os escalões inferiores de supervisão são de uma deficiência clamorosa, mas a devoção e a fidelidade de um pequeno grupo de funcionários, ao que se saiba sem maiores recompensas nem reconhecimento pelo esfôrço despendido, assegura o desempenho das tarefas essenciais. São os "burros de carga", que salvam a situação com uma espécie de liderança à moda da casa.

Talvez a maior contradição de tôdas seja oriunda do espirito de tolerância do trabalhador brasileiro. De um lado, merece encômios a facilidade com que aceita os fatôres de perturbação e desculpa as deficiências do colega, mas em têrmos práticos de administração essa atitude é capaz de levar a consequiências desastrosas: os propósitos e objetivos da Organização podem ser completamente abandonados em favor de interêsses de caráter pessoal, e quem perde, afinal, é o público.

Pior que tudo, porém, é a suspeita, até certo ponto justificada, de que essa atitude de tolerância possa conduzir a um grau maior de aceitação da corrupção, como se pode deduzir, por exemplo, do fato de que a falsificação do livro de ponto não é considerada violação maior das normas de ética; e parece meio ingênuo distinguir, segundo as boas ou más intenções de cada um, o "sujeito bom" do "sujeito mau", quando ambos praticam o mesmo ato de corrupção. 
Que recomendações devem ser feitas à base dêste estudo tão limitado? Evidentemente nenhuma, tendo em vista a natureza dos dados utilizados, o que, entretanto, não exclui certas observações. Acima de tudo, cumpre levar em conta que no Brasil a escala de valôres é predominantemente humana: onde quer que se manifeste um conflito entre a condição humana e a eficiência do sistema, a probabilidade é que vença a primeira. Portanto, ao armar uma estratégia de reforma, é importante atuar dentro de certos parâmetros, que não ameacem o bem-estar dos funcionários existentes.

$\mathrm{O}$ aspecto mais animador é o campo geralmente fértil que se encontra para o treinamento nos escalöes inferiores. Parece existir um certo consenso de que a impropriedade de comportamento é fruto mais de falta de instrução e treinamento, que de más intenções. Dai a esperança de que em grande parte êsses problemas possam ser resolvidos, e bastante progresso realizado no sentido da dignificação humana, por meio de programas de treinamento mais eficazes.

Mas o treinamento dos chefes é outra história. Nesse assunto, parece que a questão só pode ser solucionada através de uma mudança de atitude no tôpo da direção, e aqui, naturalmente, entram em conflito os valôres de um sistema politico populista e de uma nação em fase inicial de industrialização. Até que se institua na alta direção um sistema que recompense a eficácia da chefia, continuará sem solução um prob!ema dos mais persistentes \& desnorteantes, referente ao "burro de carga" no Serviço Público. 